\title{
HYGROPHORACEAE
}

\section{HYGROCYBE Kummer}

The species belonging to this genus can be recognised by their bright colours, and grow usually on the soil, in open fields, meadows, mountain slopes, lawns and dense forests. The cap is either viscid or dry, often bright red or bright yellow, or fire-red, more rarely violet, green, or pink, or dull coloured, or colourless. In brightly coloured forms the gills are either decurrent to adnexed, or adnexed to sinuate; in dull coloured and colourless forms the gills are usually non-decurrent. Spore print white; spores smooth, thin-walled, non-amyloid, uninucleate or more rarely binucleate; basidia two- or four-spored; cystidia sometimes present, filamentous. Hymenophoral trama subregular or regular. Stipe striate or smooth, dry or glutinous. Context mild, more rarely bitter, latex absent.

Distribution: nearly cosmopolitan.

Practical importance: nearly all species are edible.

\section{HYGROCYBE FIRMA (Berk. \& Br.) Singer}

This scarlet-red species has been reported from many tropical countries. Cap convex, becoming expanded, slightly umbilicate in the centre, non-viscid, silky, with minute scales towards the central disc; margin involute and lobed; gills broadly sinuate to short decurrent, pale orange, thick; edge concolorous, entire. Stipe $\mathrm{I} \cdot 5-4 \mathrm{~cm}$ long, equal or becoming wider towards the cap, hollow, pale orange-yellow, smooth with a rough base which is covered with sharppointed hairs, and a pruinose apex. Flesh thin, soft, concolorous with surface of stipe, consisting of loosely interwoven, thin-walled hyphae. Hymenophoral trama regular, hyaline or nearly so, consisting of thin-walled, much inflated hyphae; subhymenial layer well developed. Cheilocystidia hyaline, thin-walled, forming a sterile gill edge, varying in shape from piriform to clavate or cylindrical; pleurocystidia absent; basidia dimorphic, large or small, clavate, or clavate to subcylindrical, four-spored; spore print pale cream; spores ellipsoid, smooth, hyaline, inamyloid, dimorphic, large, 9·7-14 $\times 5 \cdot 2-8 \mu \mathrm{m}$, or small $5.5-8.5 \times 4-5.3 \mu \mathrm{m}$. All hyphae have clamp connections.

Distribution: widespread in tropics, mostly in Ghana, Nigeria, Congo, Trinidad, Mexico, Malaya and Ceylon.

Practical importance: edible. 